\title{
Jump Bidding Strategies in Internet Auctions**
}

\author{
Robert F. Easley \\ Department of Management \\ Mendoza College of Business \\ University of Notre Dame \\ Notre Dame, IN 46556-5646 \\ reasley@nd.edu
}

\author{
Rafael Tenorio \\ Department of Economics \\ DePaul University \\ 1 E. Jackson Blvd. - Suite 6200 \\ Chicago, IL 60604 \\ rtenorio@condor.depaul.edu
}

* We thank two anonymous referees, an Associate Editor, the Departmental Editor, Gabriella

Bucci, David Hartvigsen, Brett Katzman, David MacKay, Jeroen Swinkels, and Charles Zheng

for useful comments. We are also grateful to Kent Daniel, David Lucking-Reiley, and Preston McAfee for fruitful discussions regarding this project. Any errors or omissions are ours.

Please address correspondence to Robert F. Easley, at the above address. 


\title{
Jump Bidding Strategies in Internet Auctions
}

\begin{abstract}
A bidding strategy commonly observed in Internet auctions is that of "jump bidding," or entering a bid larger than what is necessary to be a currently winning bidder. In this paper, we argue that the cost associated with entering on-line bids and the uncertainty about future entry -both of which distinguish Internet from live auctions- can explain this behavior. We present a simple theoretical model that includes the preceding characteristics, and derive the conditions under which jump bidding arises in a format commonly used for on-line trading, the ascending-price auction. We also present evidence recorded from hundreds of Internet auctions that is consistent with some of the basic predictions from our model. We find that jump bidding is more likely earlier in an auction, when jumping has a larger strategic value, and that the incentives to jump bid increase as competition increases. Our results also indicate that jump bidding is effective: jump bidders place fewer bids overall, and increased early jump bidding deters entry later in the auction. We also discuss possible means of reducing bidding costs, and evidence that Internet auctioneers are pursuing this goal.
\end{abstract}

\section{Introduction}

The last few years have witnessed a tremendous proliferation of various forms of electronic transactions. Recent estimates place the number of U.S. households that shop on line at about 35 Million in 2003, compared to fewer than 10 Million in 1998. Although the majority of electronic transactions are based on posted-prices, auctions have become a popular means of selling commodities on the Internet. Lucking-Reiley (2000) reports that about \$1 Billion worth of 
goods were sold in Internet auctions in 1998, and this figure has grown exponentially. Estimates for 2003 are in the order of $\$ 37$ Billion. ${ }^{1}$ The spectrum of goods sold at these auctions has increased considerably, and includes computers and electronics (new and refurbished), collectibles, toys, trading cards, books, music, and many other items. Large merchandisers, like Amazon.com and Sam's Club have opened auction sites where a broad range of consumer products is offered every day.

Internet auction sites can be classified in three groups: business-to-business (B2B), business-to-consumer (B2C), and consumer-to-consumer (C2C). Although B2B auction sites have become increasingly popular in the last few years, we do not address them here due to inaccessibility of auction data for non-registered users. In B2C auction sites, or merchant sites (e.g., uBid, Egghead), the items offered come directly from manufacturers. Here, the auction site plays the role that a retailer would play. Typically, these sites offer more than one unit of the same item for sale in a single auction. In contrast, $\mathrm{C} 2 \mathrm{C}$ sites, or listing sites (e.g., eBay, Yahoo! Auctions), facilitate person-to-person transactions by creating virtual marketplaces where private bidders and sellers can get together. Most auctions in listing sites are for single items.

A popular format in all of the merchant sites is the "Yankee Auction ${ }^{\circledR} . "{ }^{2}$ This format is a variation of the multi-unit ascending (or "progressive") auction described by Vickrey (1962),

\footnotetext{
${ }^{1}$ Authors' calculations based on eBay's reported gross merchandise sales for 2003, and an eBay Internet auction market share of about $65 \%$ (as reported by the Nielsen Net ratings).

${ }^{2}$ This name was an originally trademark of Onsale.com. In the summer of 1999, Onsale.com merged with Egghead.com, which retained Onsale auctions as part of its business.
} 
and Ortega-Reichert (1968). ${ }^{3}$ Its characteristics are: (a) there are several identical units for sale; (b) each bidder may purchase more than one unit, but all units must be demanded at the same price; (c) bidding takes place progressively until a predetermined time expires; ${ }^{4}$ (d) all winning bidders pay their own prices; and (e) ties are broken on a quantity first then time basis. ${ }^{5}$ Each auction specifies minimum starting bids and bid increments.

An important feature of Yankee-type auctions, and most other Internet auctions, is that the cost of participating is different from its counterpart in live auctions. In live auctions, there may be a fixed cost of participating (opportunity cost of time plus possible entry fees), but once a bidder is at the auction the cost of entering each bid is zero. On the other hand, Internet auctions take place over a longer period, and bidders are likely to incur a cost every time they place a bid. This is because (a) there is an Internet connection cost, and (b) there is an opportunity cost associated with logging on to the site, filling out the bidding form (and confirming it), and

\footnotetext{
${ }^{3}$ Yankee-type auctions are most commonly encountered in B2C auctions. EBay, the dominant site in $\mathrm{C} 2 \mathrm{C}$ auctions, uses a different format, that of "automatic bidding." See Roth and Ockenfels (2002) for details on how the eBay format works.
}

${ }^{4}$ This is typically at least 24 hours. Some sites have soft deadlines and apply an activity rule after the posted end of the auction. This rule usually states that the auction will be closed after five or ten minutes have gone by since the last bid was made.

${ }^{5}$ This means that if two bidders enter the same bid price, the one that bids for more units ranks higher. If both bidders bid for the same number of units, the one that placed the earliest first bid ranks higher. 
preparing and entering the bid itself. ${ }^{6}$ Auction sites spare participating bidders monitoring costs by sending e-mail or pager notices when their bid is displaced from the current winning set.

Some sites (e.g., eBay and Yahoo! Auctions) allow bidders to privately enter their reservation price, or maximum willingness to pay, into a "proxy" or automatic bidding program. This automatic bidder will set the bid at the minimum level needed to outbid the next higher bidder, and based on this rule, raise the bid up to the reservation price if necessary. Traditionally, this strategy, also known as the "ratchet" strategy, has been shown to be part of an equilibrium in ascending auctions with no bidding costs and smooth exogenous bid increments. ${ }^{7}$

In this paper we develop a simple model where the presence of bidding costs may induce bidders to move away from ratchet strategies in Yankee-type auctions with private values. ${ }^{8} \mathrm{We}$ derive conditions under which bidders enter jump bids (bid increments that are larger than the minimum) in an equilibrium of the model. Bidders use these jump bids to credibly signal their valuations to potential subsequent bidders in the auction. These signaling bids ${ }^{9}$ are credible because low-valuing bidders would find it too costly to signal high values even if that would mean others would interpret them as high-valuing.

\footnotetext{
${ }^{6}$ Depending on site congestion and connection speed, it may take several minutes to complete the process of logging-on, signing-in, and entering and confirming a single bid.

${ }^{7}$ See for instance Vickrey (1962). This version of the ascending auction is known as the English "clock" auction. Isaac et. al. (2002) show that the ratchet strategy is not necessarily part of a Nash equilibrium in non-clock (or field) implementations of the ascending auction.

${ }^{8}$ A private value is one that is idiosyncratic to each bidder. For modeling purposes, each bidder is assumed to know her value but faces uncertainty about other bidders' values.

${ }^{9}$ Hereafter, the terms signaling bid and jump bid are used interchangeably.
} 
Our model is closely related to that of Daniel and Hirshleifer (1998) -henceforth D\&Hwho present an exhaustive equilibrium analysis of a costly sequential bidding model with two bidders. Using takeover bidding as a motivation, they establish that the presence of bidding costs ${ }^{10}$ may induce bidding delays and jump bids in "spontaneous" ascending auctions, i.e., auctions without a predetermined bidding increment. While our approach borrows significantly from theirs, their focus is on the effect of bidding costs on the participation decision and bidding delays. Instead, we focus on explaining what auction and bidder characteristics influence the bidders' decisions to enter jump bids in a possible equilibrium of the auction.

We present a number of testable predictions compatible with the model, and use bidding data from 236 Internet auctions to analyze these predictions. Our data indicate that jump bidding is very common. Of the 11120 bidders in our sample, 33.6\% (3731) place jump bids, with $32.3 \%$ (3595) of first bids placed as jump bids. Given that the bulk of prior work on ascending auctions has focused on ratchet bidding, this alone underscores the need for a modeling approach that accommodates jump bidding as a feasible strategy. Among our findings are that jump bids are directly related to the extent of expected competition, and that jump bidding is more likely earlier in an auction, when it has greater strategic value. Although we cannot empirically capture the act of a potential bidder being deterred by a jump bid, we find indirect evidence of such effect. Jump bidding activity early in an auction reduces the number of bids placed in the auction, and bidders whose first bid is a jump bid are less likely to place any subsequent bids.

${ }^{10}$ Bidding costs in the D\&H model mainly arise from preparing and announcing a bid. However, their formulation is general enough to accommodate any form of transaction cost. 
Avery (1998), in a related model, shows that strong bidders can effectively use jump bids as signals in auctions with affiliated values. ${ }^{11}$ Such signals let weak bidders know that entering the bidding contest may result in a high probability of incurring the winner's curse. Because of value affiliation, jump bidding is admissible even in the absence of bidding costs, and repeated jumps are possible in sequential contests, which stands in contrast to the costly bidding case, where jump bidders bid only once. ${ }^{12}$ Our data are broadly consistent with the costly bidding model, as 3515 (94.2\%) jump bidders jump once per auction. The remaining 216 jump bidders are divided between 170 (4.6\%) who jump twice, and $46(1.2 \%)$ who jump more than twice. ${ }^{13}$

A number of recent papers have studied bidding at eBay, the major listing site for $\mathrm{C} 2 \mathrm{C}$ auctions. ${ }^{14}$ However, because of eBay's automatic bidding format, none of these studies is able to examine jump bidding. Bapna et. al. (2001) classify jump bidders as "evaluators," and we present a theoretical rationale for the behaviors associated with this type, as well as further

${ }^{11}$ Affiliation is a property closely related to correlation. Two values are affiliated if a bidder drawing a high value makes it more likely (or at least not less likely) that another bidder also draws a high value. In an affiliated value auction, if a bidder wins the auction but overestimates the object's true value, that bidder has fallen prey to the "winner's curse."

${ }^{12}$ Avery's model also yields one jump bid per bidder in the presence of costly bidding.

${ }^{13} 69 \%$ of bidders in the sample bid in only one auction. An additional $15 \%$ bid in two auctions, and $99 \%$ of bidders bid in 8 or fewer auctions in the sample.

${ }^{14}$ Bajari and Hortaçsu (2003), find that costly entry is important to understanding bidding behavior in these auctions. Roth and Ockenfels (2002) study the strategic issues associated with "last minute" bidding at both eBay and Amazon.com auctions. Finally, Wilcox (2000) finds that experienced bidders behave in ways that are more consistent with traditional auction theory. 
empirical evidence of the existence of such bidders. We present the model in Section 2, our data in Section 3, the empirical analysis in Section 4, and conclude in Section 5.

\section{Model}

There are two identical risk-neutral bidders who will potentially compete to buy one unit at an ascending Internet auction. ${ }^{15}$ The minimum bid is $\underline{b}$, and each bidder holds a non-negative private valuation for the unit denoted $\mathrm{v}_{\mathrm{i}}(\mathrm{i}=1,2)$. Both bidders draw their valuation independently from the distribution $\mathrm{f}(\bullet)$ with support $[\underline{\mathrm{v}}, \overline{\mathrm{v}}]$, where $\overrightarrow{\mathrm{v}}>\underline{\mathrm{b}}$. Bids can be any number $\geq \underline{\mathrm{b}}$.

There is demand uncertainty in the following sense: The first or "early" bidder (B1) arrives to the auction site for sure, and the second or "late" bidder (B2) arrives with an exogenous and commonly known probability (1-q). ${ }^{16}$ If the second bidder finds the auction she endogenously decides whether to enter a bid or not based on the current information available at the auction site, which includes the first bidder's bid. We assume that bidder arrival is predetermined, and that each bidder knows their order of arrival. The value of each bidder's current high bid is denoted $b_{i}(i=1,2)$, and the highest bidder at the end of the auction will take the object. Because bidders draw their valuations from a continuous distribution, equal valuations occur with probability zero.

Every time a bidder signs-in to the site, places, and confirms a bid, she incurs a cost $\mathrm{c} \geq 0$. This transaction cost, which we may interpret as an opportunity cost of time and/or connectivity

\footnotetext{
${ }^{15}$ A model with three bidders and two units yields qualitatively comparable predictions.

${ }^{16}$ For a general formulation of an auction model with a stochastic number of bidders, see McAfee and McMillan (1987).
} 
cost, is common to both bidders, and does not change as the auction progresses. Bidders are free to revise their bids as many times as they want, consistent with a "soft" bidding deadline in an Internet auction. ${ }^{17}$ Once bidders find the auction and place a bid, the auction site will notify them via e-mail or pager if outbid later in the auction. Since this notification includes the value of the new high bid, early bidders do not incur a cost to gather further bid information as the auction progresses. Thus our bidding cost arises solely from the bidding process, i.e., it is a pure transaction cost.

Our model is a variation of $\mathrm{D} \& \mathrm{H}$, in which the demand uncertainty creates an asymmetry in the distributions from which the bidders draw their private valuations. In fact, we could simply view B2 as drawing a valuation equal to $\underline{\mathrm{v}}$ with probability $\mathrm{q}$, and equal to $\mathrm{v}_{2}$ with probability 1-q. Since D\&H's model accommodates asymmetric bidders, with the appropriate modifications, most of their basic results will apply to our case as well.

D\&H consider a possible preamble to the actual bidding by allowing relatively lowvaluing bidders to "pass" if it is not ex ante profitable for them to participate given the available information. If a passing bidder then observes her opponent passing as well, she will use that information to update her prior beliefs about the opponent's value, re-evaluate her expected profitability from participating, and potentially enter a bid later in the auction. However, in an Internet auction, a low-valuing bidder who passes with the intent of coming back periodically to gather information about the auction, stands to incur search costs which directly relate to her potential participation and bidding decision, and thus are not sunk. As such, unlike the D\&H model, this form of passing is costly, and a preamble where low-valuing bidders repeatedly

\footnotetext{
${ }^{17}$ In practice, this is an activity-based rule. Typically, after the posted close of the auction, bidding remains open as long as someone has placed a bid within the last five or ten minutes.
} 
reconnect prior to actually bidding is highly implausible and would most likely result in wasteful outcomes. Thus, we simply assume that if a potential bidder does not find it profitable to enter a bid at the outset, she walks away from the auction and attains some non-negative and exogenous reservation utility denoted $u_{\circ}{ }^{18}$ The bidding process is illustrated in Figure 1.

\section{(Figure 1 about here)}

\subsection{Ratchet Solution}

As shown in many previous studies, if bidding costs are negligible, i.e., $c=0$, the equilibrium in the auction we just described is the same as that of an ordinary progressive auction (Vickrey, 1962). In our model, if only the first bidder enters the auction, she will take the unit at the minimum price $\underline{b}$. Alternatively, if both bidders enter, bidding will progress smoothly until the price reaches the valuation of the lowest-valuing bidder. ${ }^{19}$

\subsection{Jump bidding Solution}

If bidders incur a positive cost each time they bid, it may not be optimal for them to use the ratchet strategy. Consider first B1's decision. Upon arriving at the auction site, he first faces the choice of participating or not. If he decides to participate, he must then choose to (a) enter a low bid and possibly have to bid again (and incur further costs) later in the presence of competition, or (b) enter a bid higher than necessary to be a current winner (i.e., a jump bid) and possibly save

\footnotetext{
18 This could arise from the utility associated with other Internet browsing activities.

${ }^{19}$ Isaac et. al. (2002) discuss possible conditions under which ratchet (or "straightforward") bidding may not necessarily be part of equilibria of auctions with non-costly bidding. Generally speaking, jumps may occur in this case if (a) bidders are impatient (i.e., want to end the auction early), or (b) bid increments are predetermined and coarse. Both of these conditions are absent in our theoretical model.
} 
bidding costs later in the auction. After B1 has made a decision, B2 arrives, with probability (1q), and considering the information displayed at the site (which may include B1's bid), decides (a) whether to place a bid or not, and (b) what the level of that bid should be. Our Proposition establishes the conditions under which each bidder participates, and what the equilibrium bid of each participating bidder is for any positive bidding cost: ${ }^{20}$

Proposition. For any $\mathrm{c}>0, \mathrm{q} \in[0,1]$, and $\mathrm{u}_{0} \geq 0$, let $\mathrm{v}^{*}$ satisfy:

$$
\left(v^{*}-\underline{b}\right)\left[q+(1-q) F\left(v^{*}\right)\right]-c=\text { uo. }
$$

There exists a perfect Bayesian equilibrium such that:

(i) If $\mathrm{v}_{1} \geq \mathrm{v}^{*}$

(a) B1 bids according to the truthfully signaling schedule

$$
b_{1}\left(v_{1}\right)=\frac{1}{\left[q+(1-q) F\left(v_{1}\right)\right]}\left[\underline{b}\left(q+(1-q) F\left(v^{*}\right)\right)+(1-q) \int_{v^{v}}^{v_{1}} s f(s) d s\right],
$$

(b) If $\mathrm{B} 2$ finds the auction, she correctly infers $\mathrm{v}_{1}$ from (1), bids $\mathrm{v}_{1}-\mathrm{c}$ if $\mathrm{v}_{2}>\mathrm{v}_{1}$, and refrains from bidding otherwise.

(c) This is supported by the out-of-equilibrium belief that if B2 submits a bid $b_{2}<v_{1}-c$, B1 believes that B2's valuation is arbitrarily close to $b_{2}+c$, and thus revises his bid to just above $b_{2}$.

(ii) If $\mathrm{v}_{1}<\mathrm{v}^{*}$,

(a) B1 refrains from bidding,

(b) If $\mathrm{B} 2$ finds the auction, she bids $\underline{\mathrm{b}}$ if $\mathrm{v}_{2}-(\underline{\mathrm{b}}+\mathrm{c}) \geq \mathrm{u}_{0}$, and refrains from bidding otherwise.

\footnotetext{
${ }^{20} \mathrm{D} \& \mathrm{H}$ demonstrate that jump bidding is also a weakly dominated equilibrium if $\mathrm{c}=0$.
} 
Proof: Follows from Proposition 3 of Daniel and Hirshleifer (1998) with two modifications:

(I) B2's valuation equals $\underline{\mathrm{v}}$ with probability $\mathrm{q}$ and is distributed according to $\mathrm{f}(\bullet)$ with probability 1-q, and (II) Each bidder's alternative to entering an initial bid is to walk away and receive nonnegative reservation utility equal to $\mathrm{u}_{0}$. See Appendix A for details.

The expression in (1) is the standard equilibrium bid function for a single-unit sealed-bid auction adjusted by two factors: demand uncertainty and costly bidding. ${ }^{21}$ Demand uncertainty causes a bidder to bid less aggressively than in a standard auction, as there is positive probability that the competitor's effective valuation will be $\underline{\mathrm{v}}$. Costly bidding, on the other hand, truncates the set of bidder types choosing to participate, and shuts out all potential bidders whose valuations fall in the interval $\left[\underline{\mathrm{v}}, \mathrm{v}_{1}^{*}\right]$. Observe that if $\mathrm{q}=\mathrm{c}=\mathrm{u}_{0}=0$ (which implies ${ }^{*}=\underline{v}$ ), (1) is identical to the equilibrium strategy in a first-price auction with minimum bid equal to $\underline{b}$.

When B1 places a jump bid, a positive and a negative effect are induced. On the plus side, a subset of B2 types (those with valuations lower than the signaled $\mathrm{v}_{1}$ ) will be deterred from placing a bid at all, thus eliminating the need to bid again and minimizing B1's expected bidding costs. On the minus side, a jump bid necessarily implies that, should B1 be the eventual winner, he will leave some money on the table, regardless of whether his bid had a deterrent effect or not. The proposition implies that, for any positive cost, the positive effect outweighs the negative

${ }^{21}$ In fact, a very interesting feature of this auction is that, adjusting for the bidding cost and demand uncertainty, B1 places the same exact bid he would place in a first price auction, while B2 places the same exact bid she would pay in an English auction. 
effect for all those B1 types choosing to participate. ${ }^{22}$ Intuitively, this arises from the fact that if B1 wins with a signaling bid, on average, he will pay the same price he would pay should he win in an English auction. However, while he pays the bidding cost once in the jump bidding equilibrium, he does it more than once if he uses a ratchet strategy. ${ }^{23}$

\subsubsection{Predictions from the Costly Bidding Model}

Taking the costly bidding model as a benchmark, we now present some basic predictions we will empirically test in subsequent sections. Although our model is single-unit, as shown elsewhere (Vickrey 1962, Ortega-Reichert 1968), the main results extend to multi-unit auctions with singleunit demands. In general, more bidders or fewer units make the environment more competitive, which increases the equilibrium level of the signaling bid.

(a) A bidder enters a higher jump bid as he anticipates more competition in the auction.

This is because a higher probability of no further entry effectively reduces the extent of potential competition. As a result, the level of the signaling bid required to exercise deterrence goes down. In terms of our model:

$$
\frac{\partial\left(b_{1}-\underline{b}\right)}{\partial q}=\frac{\int_{v_{1}^{*}}^{v_{1}}(\underline{b}-t) f(t) d t}{\left[q+(1-q) F\left(v_{1}\right)\right]^{2}}<0
$$

\footnotetext{
${ }^{22}$ Thus, although the down side of jump bidding is potentially larger in our model (because of demand uncertainty), D\&H's claim that very small costs may result in large jumps, extends to the similar auction we study here.

${ }^{23}$ We thank an anonymous referee for suggesting this insight.
} 
As the probability of no further entry approaches one, the size of the jump nears zero (i.e., $\left.\mathrm{b}_{1}\right|_{\mathrm{q}=1}=\underline{\mathrm{b}}$ ). This prediction extends to multiple units and bidders since, in each case the signal would be targeted to the bidder that would just be excluded from the set of winners, i.e., the order statistic of the highest rejected bid.

(b) The size of the jump is inversely related to the minimum starting bid.

Because all jumps are measured relative to the minimum bid, a higher minimum starting bid will truncate the distribution of jump bids from below. In terms of the model:

$$
\frac{\partial\left(\mathrm{b}_{1}-\underline{\mathrm{b}}\right)}{\partial \underline{\mathrm{b}}}=\frac{\mathrm{q}+(1-\mathrm{q}) \mathrm{F}\left(\mathrm{v}^{*}\right)}{\mathrm{q}+(1-\mathrm{q}) \mathrm{F}\left(\mathrm{v}_{1}\right)}-1<0
$$

This prediction is not affected by the number of bidders or items, since it depends only on the value of the minimum bid relative to the distribution $\mathrm{f}(\bullet)$.

(c) A bidder who jumps on the first bid is more likely to place no additional bids than one who does not.

In the equilibrium of our model, when $\mathrm{c}>0$, any participating B1 bids once and only once, and that bid is a jump bid (as long as B2 adheres to her best response strategy). Thus, hypothesis (c) does not strictly follow from the model. On the other hand, if $\mathrm{c}=0, \mathrm{~B} 1$ will likely engage in ratchet bidding, and continue to submit ratchet bids as in a standard ascending auction. Thus, extending our model to include a mix of bidders with zero entry costs and with positive entry 
costs can be expected to generate the pattern hypothesized in (c). ${ }^{24}$ This is because B1 who jump bids must have $\mathrm{c}>0$, and therefore will not bid again, while any $\mathrm{B} 1$ who does not jump bid may possibly bid again later. Prediction (c) hinges solely on the presence of bidding costs, so that it holds for multiple units and bidders as well.

(d) For a given level of potential competition, an auction with larger early jump bids will have fewer bids placed overall.

Since an early bidder places a jump bid with the intent of deterring subsequent bidders from entering, given a probability of further entry, the extent of this deterrence will be proportional to the level of the initial bid. In terms of the model, by monotonicity of the bid function, for a given q, the higher $\mathrm{B} 1$ 's valuation the more $\mathrm{B} 2$ types will be deterred, and the higher the probability that we will observe only one bid placed in the auction. ${ }^{25}$ This argument extends to

${ }^{24}$ Developing a model that has bidders with $\mathrm{c}=0$ and with $\mathrm{c}>0$ coexisting is beyond the scope of this paper. Therefore, we base this prediction on nesting the results of the two different types of equilibria arising from our simple model.

${ }^{25}$ In the model, the probability that the second bidder will enter is $(1-\mathrm{q})\left(1-\mathrm{F}\left(\mathrm{v}_{\mathrm{v}}\right)\right)$, and thus as B2's entry becomes more likely (i.e., lower q), the probability of a second bidder increases. However, that increase is entirely through $\mathrm{q}$, and it is not affected by $\mathrm{F}\left(\mathrm{v}_{\mathrm{l}}\right)$. Thus, a higher initial jump bid implies fewer subsequent bids only if the higher jump bid is due to $\mathrm{v}_{1}$ being higher, because then more B2's are deterred from bidding. But it could mean more subsequent bids if the higher jump bid is because, for a fixed $\mathrm{v}_{1}, \mathrm{~B} 1$ bids higher because $\mathrm{q}$ is lower. In this case B2 shows up more frequently, and is not deterred more often by the higher bid by B1, with the overall result that subsequent bids tend to increase. Thus we are careful in stating this prediction 
multiple units and bidders, as the higher early bids will deter a larger subset of potential competitors given any number of units sold.

This prediction does not imply that bidders who (jump) bid early are more likely to win the auction than bidders who would bid late, since those deterred from entry are deterred precisely because their valuation is lower than that one signaled by the jump bid. When effective, signaling excludes bidders with lower valuations, and thus does not affect the initial bidder's probability of winning.

(e) A bidder that bids early in the auction enters a higher jump bid than one bidding later in the auction.

This prediction does not follow from the model under general conditions, but we explore it given its intuitive appeal and the nature of the bidding data we use. As discussed before, an early bidder choosing to participate places a jump bid. If a later bidder is not deterred by this initial jump bid, she will (correctly) infer the valuation signaled by the early bidder and place a bid to just preempt further bids from the initial bidder. We can show that for a family of parameter configurations, the jump implied by the late preemptive bid is smaller than that of the initial bid relative to $\underline{\mathrm{b}} .{ }^{26}$

on the condition that $\mathrm{q}$ is fixed, and as such we must adequately control for this variable in the empirical analysis. We thank an Associate Editor for bringing this point to our attention.

${ }^{26}$ A necessary and sufficient condition for this to hold is that, on average, for all B1's choosing to participate, $2 b_{1}\left(v_{1}\right)-v_{1}$ exceeds $\underline{b}-c$. This holds for certain combinations of valuation densities, minimum bids, and bidding costs. For instance a uniform value distribution, a zero starting bid and any positive bidding costs validate this condition. 


\section{Data}

We recorded data from multi-item auctions at two different Internet auction sites, Onsale.com and uBid.com, using a computer program that ran continuously. The two auction sites specialize to a large extent in consumer electronic and computer products, and offered both new and refurbished items, usually with the item's manufacturer as the seller. Since the items were auctioned for original manufacturers or distributors, and not for individuals, any effect of uncertainty about delivery and warranty on prices is minimal.

All auctions in our sample ran approximately 24 hours. The data collection program recorded the current winning bid information for each auction every 15 minutes until the final half-hour before the posted closing time of the auction. During this final period, when bidding activity typically accelerates, the program collected this information every few minutes until the auction finally closed, following activity-based closing rules. On both sites this rule specified that, after the posted closing of the auction, bidding would stop when no bid had been received in the last five (Onsale) or ten (uBid) minutes. We compared each new set of bid data to the previous round to see if any change had occurred in bid values or currently winning bidders. If so, we kept the data, and if not, we discarded it as redundant. On average, we discarded $77 \%$ of the collected data for this reason. We then examined the auction data for any gaps in recorded bidding activity ${ }^{27}$ by tracking the position of the highest bidder in subsequent rounds. With multi-item auctions, the highest bidder cannot be eliminated from the posted currently winning

\footnotetext{
${ }^{27}$ In general, any gaps in recording resulted from interruption of the Internet connection or related technical problems.
} 
bids by a single new bid. We eliminated auctions with missing bid data; that is auctions with gaps in recorded bidding activity during which the highest bidder was displaced.

Table 1 presents descriptive statistics for the 236 auctions that remain in our sample. On average, an auction would offer 11 units, with 55 bids placed by 47 bidders. The mean, taken across all auctions, of the per-auction average price paid for each item by a winning bidder, was $\$ 682$. The difference between average price paid and starting bid, in bid increments (not shown in table), has a mean of 43 , a median of 23 , and a maximum of 270 . Posted list prices were available for all uBid auctions (where it is called "maximum bid price"), and for about $25 \%$ of the Onsale auctions (where it was an optional item) in the sample. For this subset of 159 auctions, the average posted list price of the items was $\$ 1735$, and the highest average winning bid observed, as a percent of list price was 58\%. Minimum (i.e., starting) bid values were generally low, but range as high as $\$ 249$, and are positively correlated with average winning bid (corr $=0.48)$ and list price (corr $=0.12) .{ }^{28}$ Minimum bid increment values, ranging from $\$ 3$ to $\$ 20$, are also positively correlated with average winning bid (corr $=0.33$ ), and list price (corr $=0.48)$.

\section{(Table 1 about here)}

In $58 \%$ (138) of the auctions in the sample, each bidder bid just once. In a typical example of this type, five Compaq Pentium II computers, with posted list price of $\$ 4899$ and a \$20 bid increment, attracted 75 bidders, who placed 75 bids, reaching a final selling price ranging from $\$ 2047$ - \$2067. At the low extreme of bidding activity, an auction of 17 units of a pager attracted only 3 bidders, each winning one unit at the minimum starting price of $\$ 29$. The

\footnotetext{
${ }^{28}$ The low correlation of minimum bid and list price is due to the concentration of list price data in uBid auctions, where minimum bids are generally fixed at $\$ 7$.
} 
largest auction, in terms of number of units, was for 61 palm pilots, with no posted list price and a $\$ 10$ bid increment, attracting 173 bidders who placed 210 bids, with a final selling price from $\$ 239$ to $\$ 299$.

For the entire sample of auctions, the average of all winning bids exceeds the average of those winning bids at the minimum winning price ${ }^{29}$ by an average of $\$ 5.40$ per auction. On a percentage basis, this excess averages $0.8 \%$ across all auctions in the sample, thus providing an indication of the economic consequences from jump bidding. However we cannot empirically ascertain whether this constitutes a positive or negative revenue effect, since the extent of entry deterrence due to costs and jump bidding is not observable.

\section{Empirical Analysis}

We perform a series of ordinary least squares (OLS) and logistic regressions to test our predictions over the appropriate data sets for each. ${ }^{30}$ All results reported in section 4.2 below are for the subset of auction data (159 auctions, 8631 bids, 8015 bidders) for which we have an exogenous item value measure - the list price - available as a control variable. The results over the full data set are generally consistent with the results reported, with differences noted as

${ }^{29}$ We define this as the average of winning bids at the lowest winning bid plus those bids one increment above the lowest, due to application of the time-of-first-bid rule, which we discuss further in section 4.1 .

${ }^{30}$ We do not test "expedience" jump bidding, i.e., that arising from the desire to save one's bidding costs with no signaling motive. As stated before, Isaac et. al. (2002) show that jump bidding may occur if bidders want to end the auction early or because of coarse bid increments. While the former is not possible in the auctions in our sample, we empirically address the latter. 
appropriate. We describe the dependent, independent and control variables used in these analyses in the following section, and report results for the subset of data with the exogenous item value measure in the subsequent section.

\subsection{Definition of Variables}

We use two different dependent variables to test two interpretations of predictions (a), (b) and (e). The first measures the magnitude of the bid gap and the second one is a binary dependent variable that flags whether a bid is a jump bid or not. The magnitude of the bid gap is simply the number of bid increments by which a new bid exceeds the minimum posted winning bid at the time of the bid. This value could be 0 if the number of bidders is less than the number of items at the time the bid is placed, or if the time-of-first-bid rule breaks a tie in favor of the new bid. Because tie-breaking rules favor the bidder who placed her first bid earlier, in some cases a tying bid will win.

Although the predictions concern the magnitude of jump bids, because we measure jump bidding in terms of bid increments, it is possible that in some instances jump bids may not be detected in the data. Thus we explore alternatives to predictions (a), (b), and (e) accounting for the fact that the larger a jump bid is, the higher the probability it will be statistically detected as a jump for any given bid increment. To implement this alternative we create a logistic dependent variable that is related to the magnitude of the bid gap as follows: Zero (not a jump) if the magnitude of the bid gap is 0 or 1 , and One (a jump bid) if this magnitude is greater than 1 . In constructing this variable we ignore the time-of-first-bid tie-breaking rule in identifying jump bids, and consider a bid gap of magnitude 1 to be a ratchet bid. ${ }^{31}$ This will slightly undercount

${ }^{31}$ In addition to only affecting a small percentage of bids in the sample, it is likely that many bidders ignore this rule. Neither auction site in the study uses this rule in posting a minimum bid 
jump bids, but given that $85 \%$ (11120 of 13080) of bids in the full sample are first bids (where time-of-first-bid rules could not favor the new bid), this makes little difference in the analysis, with any resulting bias providing a more conservative measure of jump bidding.

To test prediction (c), we again use two dependent variables, the total number of bids per bidder, and a binary version of this variable indicating whether the bidder entered more than one bid. We perform this analysis on the 8631 bidders who place bids in the subset of recorded auctions with list price data available. Finally, unlike the previous cases, we test prediction (d) at the auction level, with the total number of bids placed per auction as the dependent variable.

All auctions in the sample were 24-hour listings, and the data include the exact time each bid is placed. The average auction duration in the sample, measuring from first recorded bid to last recorded bid, was 23.5 hours, with a variance of 2.5 hours. The variance was due both to time passing prior to the first recorded bid, and extension of the bidding past the posted close due to activity-based closing rules. Auctions in the sample ended between 0 and 147 minutes past the posted closing time, with an average extension of 23 minutes. Table 2 shows the distribution of bids across auction time, measuring from the close of the auction. Approximately one third of bids occur during the first six hours of an auction, one fourth during the last 90 minutes, and most remaining bids early on the closing day rather than the night before. To control for variance in auction duration, the independent variable, Percent Time of Bid, is the time the bid is placed expressed as a percentage of elapsed auction time, with a value of 0 indicating the start of the auction and 100 the end of the auction.

needed to win. Instead, uBid posts a single value that ignores the time-based rule as well as the quantity-based rule, and Onsale posts the range of currently winning bids. We do not consider bid quantity in defining jump bids. 


\section{(Table 2 about here)}

The independent variable Number of Bidders is the number of bidders who enter bids in the auction. This value is unknown to bidders during the auction, except approximately or in expectation, and with decreasing uncertainty as the auction progresses. We are not able to capture the act of a potential bidder examining posted currently winning bids, and then declining to bid. Though this would clearly be useful in establishing bid deterrence, this data would only be available to the site running the auction, and then only if they chose to record it. ${ }^{32}$

The auctions often attracted bidders interested in a large number of units, who were often judged to be dealers by other bidders, based on posted optional comments attached to their bids. Frequently, these bidders would appear early in an auction, and then disappear as bid levels increased. To control for any distortion the presence of such bidders might produce, we label an auction where some bidders place more than two-unit bids as having "dealer presence." ${ }^{33} \mathrm{We}$

${ }^{32}$ Throughout most of the analysis we use actual number of bidders as a proxy for potential number of bidders. Although the use of this proxy is potentially subject to endogeneity problems, we believe this is a reasonable proxy because it just signals that auctions with many participating bidders (i.e., large auctions) tend to attract a larger set of potential bidders. Because actual number of bidders is only a subset of potential number of bidders, our results are conservative: since this proxy is an independent variable, our results are likely weaker than they would be if we used the - unobservable - potential competition.

${ }^{33}$ There are some possible distortions. First, the presence of multi-unit demand bidders may introduce asymmetries into the auction. Second, if these bidders are dealers, because of a resale motive, their values are more likely to have a common or correlated element. Finally, since 
base our decision to mark bids for three or more items as dealer bids on the distribution of maximum quantities requested per auction, shown in Table 3, as well as on the plausibility of buying two of an item for personal use. This results in the labeling of 70 auctions, or $29.7 \%$ of the auctions in the sample, as having dealer presence. In our analysis, the control variable for dealer presence never attains significance, and "dealers" tend to enter jump bids with approximately the same frequency as other bidders. ${ }^{34}$

\section{(Table 3 about here)}

To control for item value we performed the analysis over the subset of auctions for which we have posted list price information, as described in the previous section. We also used the average of all winning bids to control for item value in the analysis over the whole data set. Since the average winning bid is not fully exogenous, we performed the latter analysis mainly as a robustness test. In fact, both the list price and average winning bid are strongly correlated. In the sub-sample of 8631 bids entered in 159 auctions with list price information, the correlation coefficient between these two variables is approximately 0.9 . We express both the list price and the average winning bid in terms of bid increments.

The remaining control variables are Units Available and Minimum Bid in Increments. The former is simply the number of units available in the auction. We classify this as low (2-5 copies of the item), medium (6-11) or high (12-61), and enter it as a series of dummy variables for the medium and high state (a continuous version of this variable yields similar results). The

these bidders' have positive valuations for several units, demand-reduction strategies may be admissible (see Ausubel and Cramton 1998, Tenorio 1997).

${ }^{34}$ Dealers are about $5 \%$ more likely, on average, to place their first bid as a jump bid (33.3\%, versus $31.7 \%$ for other bidders). Dealer bids overall are about $1 \%$ more likely to be jump bids. 
latter is the posted minimum (starting) bid, expressed in bid increments to maintain consistency with the normalization of the two item-value measures discussed above. We do not include Bid Increment itself as a control variable because we use it to normalize other variables.

\subsection{Results}

Table 4 presents the results of two regression analyses, testing slightly different interpretations of the first two predictions. Prediction (a) concerns the effect of anticipated level of competition on both the probability of jump bidding and on the size of the jump bid. The coefficients for Number of Bidders in Table 4 are positive and significant for both regressions. The logistic regression results suggest that the marginal effect of increasing the number of bidders drives the probability of jump bidding up from $31 \%$ with just 3 bidders, to $42 \%$ with 253 bidders. The OLS regression results are consistent with these results, showing the magnitude of bid gap increasing in the number of bidders. As we stated before, the observed number of bidders is a conservative measure of competition, since the true number of bidders (including those who arrived but were deterred from bidding) would be weakly larger. It is interesting to note that although the expected number of bidders is not known, bidders appear to be able to form reasonable predictions of this value. In fact, we observe that in all auctions ( 8 of 236) where the number of bidders is ex post lower than the number of units, jump bidding does not occur at all.

\section{(Table 4 about here)}

Prediction (b) suggests that a higher minimum bid should result in smaller jump bids. This is supported by the results, which show a significant and negative marginal effect of increasing minimum bids on both the probability and size of jump bids. This is the only result reported that differs over the full data set, where the coefficient remains negative, but is no 
longer statistically significant. Obviously, controlling for list price, which is not possible for the full data set, is important in gauging the effect of the minimum bid.

Prediction (e) represents an interesting alternative to prediction (a), since it addresses two potential concerns: first that the number of bidders is itself affected by the presence of jump bids, and second that the number of bidders is an imperfect measure of the potential competition in an auction, since it is measured ex post and is not known to the bidder at the time a bid is placed (although that uncertainty decreases as the end of the auction nears). An alternative is to interpret the amount of time remaining in the auction as a proxy for the expected level of competition. Under this interpretation, we omit Number of Bidders as an independent variable, since we simply assume that the level of competition declines as the auction progresses. Table 5 presents the same analysis that is conducted in Table 4 but omitting Number of Bidders. On both tables, on both regressions, the coefficient for Percent Time of Bid is negative and statistically significant. The logistic regression results imply that the marginal effect of moving from the beginning to the end of the auction drives the probability of entering a jump bid down from $31 \%$ to $8 \%$. The OLS regression results indicate that as time passes, the expected magnitude of the bid gap registered with a new bid will decrease, consistent with the reduced probability of entering a jump bid. ${ }^{35}$

\section{(Table 5 about here)}

In general the results in Tables 4 and 5 are quite consistent. For example, the effect of the minimum bid is negative and significant in both cases. The largest exception to this is that the Units Available dummy variable coefficients, though positive in both tables, vary in statistical significance. In both cases the coefficients for List Price are positive and significant,

${ }^{35}$ This also holds conditional on observing a jump bid. See Appendix B. 
indicating that both the magnitude of the bid gap, and the probability of entering a jump bid, increase with item value. This is not surprising for a number of reasons, the simplest being that a jump bid is more easily detected - and therefore signaling is more effective - with higher-valued items. Bid increments are not observed to be larger than $\$ 20$, thus a jump bid is also less likely to round to a single bid increment with higher-valued items. The Dealer Presence variable is never significant across any of our analyses, indicating that bids for large quantities, while eliciting occasional anti-dealer comments, do not appear to affect jump bidding behavior.

Although the data support the basic predictions concerning the incentives for jump bidding, the question remains whether jump bidding has the intended effect when bidders employ it. First, does a bidder who places a jump bid actually reduce her cost of bidding by placing fewer bids? Table 6 presents the results of analysis over the set of all bidders who participated in auctions for which we have list price information. The dependent variables here are a flag indicating whether the bidder placed more than one bid, and the number of bids placed by an individual bidder. We also introduce a new independent dummy variable indicating whether that bidder jumped on her first bid or not. The coefficients in both regressions for the Jump on First Bid variable are statistically significant and negative. This indicates that the marginal effect of jumping on the first bid leads to a reduced total number of bids placed, and to a reduced probability of bidding more than once, thus lending support to prediction (c).

\section{(Table 6 about here)}

Prediction (d) makes a related point for auctions rather than bidders. If signaling bids are effective, then, for a given probability of further entry, larger signaling bids early in an auction 
should lead to fewer overall bids. ${ }^{36}$ In the analysis presented in Table 7 , we regress the total number of bids at an auction on the average magnitude of jump bids, measured in bid increments, over the first $10 \%$ of elapsed auction time, for the list price data subset. ${ }^{37}$ Since the average magnitude of jump bids may be related to the list price of the item, we also consider an alternative model including the interaction of both variables (see Panel 2 of Table 7). Because the average jump and the interaction term are highly correlated $(\rho=0.86)$, the interaction term, although statistically insignificant, lowers the significance of the average jump variable (to a $10 \%$ level) and adds nothing to the model's explanatory power. In fact, because of the high collinearity between these two variables, one can almost perfectly substitute for the other in our regression model (see Panel 3 of Table 7). Overall, the results indicate that stronger signaling bids early in the auction lead to a lower number of bids for the entire auction, thereby providing some indirect evidence of bid deterrence.

\section{(Table 7 about here)}

\section{Discussion and Conclusions}

In this paper we have presented simple theoretical arguments to explain why bidders may choose to follow jump bidding strategies in auctions with bidding costs. Using an uncertain demand extension of a model by Daniel and Hirshleifer (1998) we showed that jump bids may play a signaling role in auctions where it is costly for bidders to place their bids. Our model

\footnotetext{
${ }^{36}$ Like before, we attempt to control for potential competition by including the number of bidders on the right hand side. The use of this proxy is subject to caveat on footnote 32 .

37 The same analysis with average magnitude of jump bids measured over the first $25 \%$ of elapsed auction time yields nearly identical results.
} 
demonstrates that any positive bidding cost leads to jump bids by bidders choosing to enter, and the size of these jump bids is related to the auction's competitive conditions.

We have also presented extensive evidence from a sample of ascending Internet auctions that supports these theoretical predictions. Our analysis shows that a very large fraction of bidders at these auctions enter jump bids and that these bids are mostly entered early in the auction, when they have greater strategic value. We also show that jump bidding is more likely in auctions where bidder competition is more intense. Finally we provide evidence that jump bidding strategies, when used, do lower the number of bids, both at the auction level, and for an individual bidder, consistent with a deterrence and cost-saving effect of jump bids.

There are a number of interesting questions that remain open, both on the bidder and seller side of auctions with costly bidding. For instance, on the bidder side we assumed that bidders arrive to the auction site on a predetermined basis. As such, timing is not part of the bidding strategy. Yet, one may argue that a strategy of waiting to bid until the final minutes of the auction may be advantageous. ${ }^{38} \mathrm{~A}$ formal analysis of this claim would probably require an asymmetric model, where higher-cost bidders self-select to bid earlier in the auction and are more likely to enter jump bids. Conversely, bidders with lower costs could afford to keep track of the bidding more closely and be active at the specific times of the day when the auctions are set to end. The downside of these timing strategies would be that if the site is very congested at the end of an auction, one may miss the chance to bid altogether. Other extensions may include more bidders or items, richer structures of uncertainty and valuations, and multi-unit demands.

\footnotetext{
${ }^{38}$ In fact a large amount of bidding activity is usually observed during the closing minutes of each auction, as seen in Table 2, and as documented by Roth \& Ockenfels (2002).
} 
There are many issues that remain unexplored on the seller side as well. For instance, D\&H show that seller expected revenue in auctions with costly bidding is smaller than its costless counterpart by a factor related to the expected bidding costs. As such, it is in the seller's best interest to undertake actions that will reduce the cost of bidding. It seems that real-life Internet auctioneers are aware of this phenomenon. We have found that sellers have introduced two practices that reduce bidding costs: automatic or "proxy" bidding, and "quick" auctions.

With proxy bidding, ${ }^{39}$ bidders may privately provide their maximum possible bid (reservation price) to a secure computer program, which will update their current high bid to the minimum necessary for that bidder to be included in the set of winners. In other words, this mechanism seeks to turn these auctions into Vickrey-like auctions and eliminate the potential costs a bidder will incur when revising her bid. A curious phenomenon is that although many auction sites offer this service as an option, not all bidders choose to use it. Among other reasons, this may be originate in bidders not fully understanding (or trusting) the way the computer program works, or perhaps they may like to retain the flexibility to revise their reservation price if value correlation exists. An additional complication introduced by proxy bidding is the introduction of heterogeneity. How should non-proxy bidders bid against proxy bidders? Is jump bidding more or less likely in these cases? These are interesting questions for future research.

The second bid-cost reducing seller practice is "quick auctions," also known as "flash auctions" or "express auctions." These are auctions where all of the bidding takes place within a short time period, usually a half-hour or an hour, so they have a bidding cost structure more similar to live auctions, with a higher fixed cost of attending, and a lower per bid cost.

${ }^{39}$ Also known as "bid agents", "bid-makers", "bid elves", or "bid butlers." 
Presumably, what auctioneers intend to do with these auctions is to attract bidders with a low opportunity cost for their time, i.e., bidders that can afford to be in front of their computers for the duration of the auction. Our preliminary analysis of a sample of these auctions reveals that no meaningful jump bidding occurs in them, i.e., they are more like live auctions. Although it is clear that low-cost bidders should be typically attracted to these auctions, the net effect over the auctioneer's revenue would ultimately depend on whether these bidders hold some other special characteristics that could affect the revenue in a well-defined way. For instance, are these bidders more likely to have lower values than the rest of the bidder population? If so, quick auction revenues could actually be negatively affected by bidder selectivity. We intend to examine this as well as other related issues in future projects. 


\section{References}

Ausubel, L., and P. Cramton (2002), "Demand Reduction and Inefficiency in Multi-Unit Auctions," Mimeo, University of Maryland at College Park.

Avery, C. (1998), "Strategic Jump bidding in English Auctions," Review of Economic Studies 65, 185-210.

Bajari, P. and Hortaçsu (2003), "Winner's Curse, Reserve Prices and Endogenous Entry: Empirical Insights from eBay Auctions," RAND Journal of Economics 34:2, 329-355.

Bapna, R., P. Goes, and A. Gupta (2001), "Insights and Analyses of Online Auctions," Communications of the ACM, 44:11, 42-50.

Daniel, K., and D. Hirshleifer (1998), “A Theory of Costly Sequential Bidding,” Mimeo, Kellogg Graduate School of Management, Northwestern University.

Isaac, M., T. Salmon, and A. Zillante (2002), "A theory of Jump Bidding in Ascending Auctions," Mimeo, Florida State University.

Lucking-Reiley, D. (2000), "Auctions on the Internet: What is Being Auctioned, and How?," The Journal of Industrial Economics 48, 227-252

McAfee, P., and J. McMillan (1987), "Auctions with a Stochastic Number of Bidders," Journal of Economic Theory 43, 1-19.

Ortega-Reichert, A. (1968), Models for Competitive Bidding under Uncertainty, Ph.D. Dissertation, Stanford University.

Roth, A. and A. Ockenfels (2002), " Last-Minute Bidding and the Rules for Ending Second-Price Auctions: Evidence from eBay and Amazon Auctions on the Internet," American Economic Review 92, 1093-1103.

Tenorio, R. (1997), "On Strategic Quantity Bidding in Multiple Unit Auctions,” Journal of Industrial Economics XLV, No.2, 207-217.

Vickrey, W. (1962), "Auctions and Bidding Games," in Recent Advances in Game Theory, edited by O. Morgenstern and A. Tucker, Princeton University.

Wilcox, R. (2000), "Experts and Amateurs: The Role of Experience in Internet Auctions," Marketing Letters, 11, 363-374. 


\section{Appendix A: Outline of Proof of Proposition}

Since our model is a variation of Daniel and Hirschleifer (1998), we will just outline the main steps involved in proving the proposition, and refer the reader to their original proof for details.

-Point (i) specifies optimal behavior for both bidders (and the beliefs that support this behavior) when the first bidder participates in the auction. For any $c>0$ and $u_{0} \geq 0$, there will be a nonempty range of B1 values that would enjoy a non-negative expected surplus from bidding. To establish this range, observe that the weakest possible B1 to participate can enter a bid equal to $\underline{b}$, and that he would be indifferent between doing so and walking away from the auction and receiving $\mathrm{u}_{\mathrm{o}}$. This indifference establishes the condition that $\mathrm{v}^{*}$ must satisfy.

To establish the bidding schedule in (1), notice that given B2's optimal response, B1's bidding problem is:

$$
\underset{b_{1}}{\operatorname{Max}}\left(v_{1}-b_{1}\right)\left[q+(1-q) F\left(v\left(b_{1}\right)\right)\right]-c
$$

where $v(\bullet)$ is the inverse of B1's equilibrium bid function. (A1) is equivalent to a bidder's problem in a first price sealed bid auction. Thus, solving the above problem and using the initial condition that the lowest-valuing B1 entering a bid is $\mathrm{v}^{*}$, i.e., $\mathrm{b}_{1}\left(\mathrm{v}^{*}\right)=\underline{\mathrm{b}}$, yields the equilibrium bid function (1). Given that $\mathrm{B} 1$ signals truthfully, if $\mathrm{v}_{2}>\mathrm{v}_{1}, \mathrm{~B} 2$ preempts $\mathrm{B} 1$ from bidding again by entering a bid equal to $\mathrm{v}_{1}$-c.

The above argument presumes that B1 will find it optimal to bid once and only once while truthfully signaling her valuation in the process. A possible defection from this strategy involves submitting a low bid (one that signals a lower valuation), then wait and see if B2 enters and submits a bid, and possibly revise the initial low bid later in the auction. In fact, it is within 
one's strategy set to bid low and revise this bid many times (perhaps even infinite) in response to later bidders entering the auction. D\&H show that such defection is never profitable on average, as the expected bidding cost(s) one would incur by having to possibly re-bid, outweighs the potential benefit arising from gaining information about B2's value by shading one's bid below the truthfully signaling level. See D\&H, Section (IV.C) for details.

-Points (ii.a) and (ii.b) specify optimal behavior for both bidders when the first bidder does not participate in the auction. Condition (a) is obvious. Condition (b) follows from the fact that in B1's absence, B2 could either incur the cost $\mathrm{c}$ and take the object at the minimum price $\underline{\mathrm{b}}$, or walk away and get $\mathrm{u}_{0}$. Indifference between these two alternatives establishes the lowest-valuing B2 that would choose to participate in this case. This completes the outline of the proof.

\section{Appendix B: Further Tests}

Table A1 shows that, even conditional on a jump bid, the magnitude of the jump bid is decreasing over the course of the auction, whether or not the Number of Bidders is included as an explanatory variable.

(Table A1 about here) 
Figure 1 Time-line for Bidding Process Assumed in Model

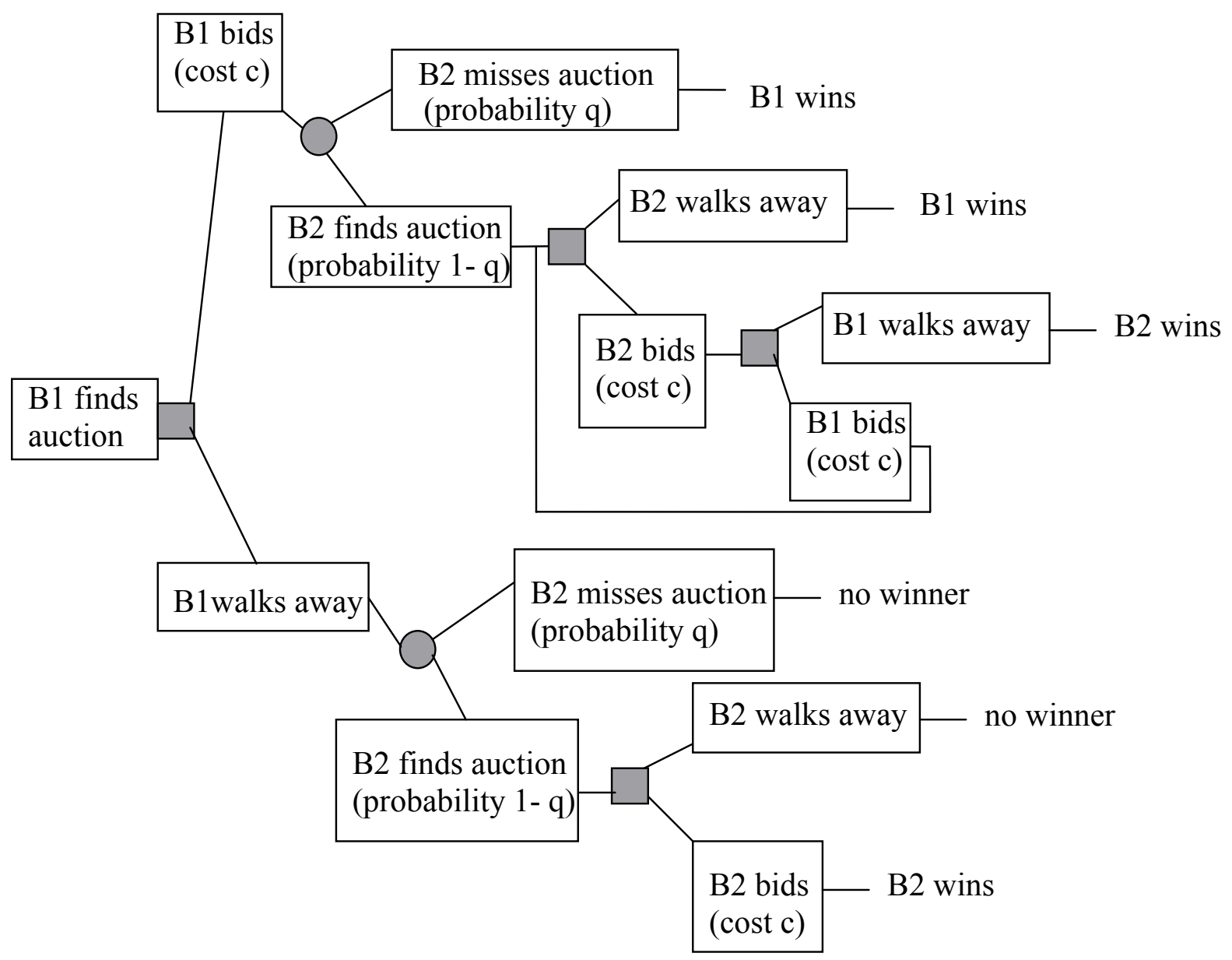


Table 1 Selected Summary Statistics for Sample of 236 Auctions

$\begin{array}{lcccc}\text { Variable } & \text { Minimum } & \text { Maximum } & \text { Mean } & \text { Total } \\ \text { Posted List Price }^{\mathrm{a}} & 120 & 7999 & 1735 & - \\ \text { Average Winning Bid }^{\mathrm{b}} & 29 & 3583 & 682 & - \\ \text { Minimum Bid }^{\mathrm{c}} & 7 & 249 & 38 & - \\ \text { Avg. Winning Bid as \% of List Price }^{\mathrm{a}, \mathrm{d}} & 18 & 58 & 39 & - \\ \text { Bid Increment }^{\text {Number of Bidders }} & 3 & 20 & 15 & - \\ \text { Units Available }^{\text {Number of Bids }} & 3 & 253 & 47 & 11120 \\ \text { Numb } & 2 & 61 & 11 & 2635 \\ \text { Posted } & 3 & 254 & 55 & 13080\end{array}$

${ }^{\text {a }}$ Posted List Price is available for only 159 of the 236 auctions.

${ }^{\mathrm{b}}$ The Average Winning Bid for the list-price data subset is 689 .

${ }^{c}$ For uBid, the highest Minimum Bid was 99, with a mean of 9, for Onsale the lowest was 9, with a mean of 137.

${ }^{d}$ Values for Maximum Bid as \% of List Price are 20, 60, and 41 respectively.

Table 2 Distribution of Bids by Time of Bid, Measured from Close of Auction

Time of Bid, from Close of Auction ${ }^{\text {a }} \quad$ Number of Bids Percent of Bids

$\begin{array}{ccc}\text { last } 90 \text { minutes } & 3245 & 24.8 \\ 1.5-10 \text { hours } & 3993 & 30.5 \\ 10-18 \text { hours } & 1452 & 11.1 \\ >18 \text { hours } & 4390 & 33.6\end{array}$

a $95 \%$ of auction closings occurred between noon and 9 p.m. PST, so the 10 -hour cutoff tends to fall during nighttime and morning hours, a bit later in the East. 
Table 3 Distribution of Auctions by

Maximum Number of Items

Requested in any Bid

$\begin{array}{ccc}\text { Maximum } & \text { Frequency } & \begin{array}{c}\text { Cumulative } \\ \text { Percentage }\end{array} \\ 1 & 99 & 41.9 \\ 2 & 67 & 70.3 \\ 3 & 21 & 79.2 \\ 4 & 21 & 88.1 \\ 5 & 7 & 91.1 \\ 6 & 6 & 93.6 \\ \text { More } & 15 & 100\end{array}$

Table 4 Logistic Regression of Jump Bid Flag and OLS Regression of Magnitude of Bid Increase

\begin{tabular}{|c|c|c|c|c|}
\hline & $\begin{array}{l}\text { Logistic Reg } \\
\text { Coefficients }\end{array}$ & $\begin{array}{l}\text { gression } \\
\text { p-value }\end{array}$ & $\begin{array}{l}\text { OLS Regre } \\
\text { Coefficients }\end{array}$ & $\begin{array}{l}\text { ession } \\
\text { p-value }\end{array}$ \\
\hline Intercept & -0.8058 & 0 & 1.7877 & \\
\hline Percent Time of Bid & -0.0164 & 0 & -0.0208 & \\
\hline Number of Bidders & 0.0019 & 0.0004 & 0.0053 & \\
\hline List Price in Increments & 0.0039 & 0 & 0.0054 & \\
\hline Minimum Bid In Increments & -0.0174 & 0.0005 & -0.0182 & 0.0009 \\
\hline 6-11 Units Available ${ }^{a}$ & 0.1570 & 0.1213 & 0.1125 & 0.3150 \\
\hline 12-61 Units Available ${ }^{\mathrm{a}}$ & 0.2648 & 0.0223 & 0.0337 & 0.7941 \\
\hline Dealer Presence & -0.0403 & 0.4714 & 0.0019 & 0.9768 \\
\hline
\end{tabular}

${ }^{a}$ For 2-5 Units Available both dummy variables $=0$.

Logistic regression pseudo R-squared $=0.086$, OLS regression adjusted Rsquared $=0.115, \mathrm{p}$-values are two-tailed tests, $\mathrm{n}=8631$. 
Table 5 Logistic Regression of Jump Bid Flag and OLS Regression of Magnitude of Bid Increase

\begin{tabular}{|c|c|c|c|c|}
\hline & $\begin{array}{l}\text { Logistic Reg } \\
\text { Coefficients }\end{array}$ & $\begin{array}{l}\text { p-value } \\
\text { pession }\end{array}$ & $\begin{array}{r}\text { OLS Regr } \\
\text { Coefficients }\end{array}$ & $\begin{array}{l}\text { p-value } \\
\text { ession }\end{array}$ \\
\hline Intercept & -0.8275 & 0 & 1.7346 & 0 \\
\hline Percent Time of Bid & -0.0163 & & -0.0206 & 0 \\
\hline List Price in Increments & 0.0044 & 0 & 0.0069 & 0 \\
\hline Minimum Bid In Increments & -0.0249 & 0 & -0.0367 & 0 \\
\hline 6-11 Units Available ${ }^{\mathrm{a}}$ & 0.2001 & 0.0468 & 0.2286 & 0.0403 \\
\hline 12-61 Units Available ${ }^{a}$ & 0.4659 & 0 & 0.5680 & 0 \\
\hline Dealer Presence & 0.0014 & 0.9795 & 0.1103 & 0.0790 \\
\hline
\end{tabular}

${ }^{\text {a }}$ For 2-5 Units Available both dummy variables $=0$.

Logistic regression pseudo R-squared $=0.084$, OLS regression adjusted Rsquared $=0.108, \mathrm{p}$-values are two-tailed tests, $\mathrm{n}=8631$.

Table 6 Logistic Regression of More Than One Jump Bid per Bidder, and OLS Regression of Total Number of Bids per Bidder

Logistic Regression OLS Regression

Coefficients p-value Coefficients p-value

Intercept

$\begin{array}{rrrr}-5.0054 & 0 & 0.8724 & 0 \\ -0.9794 & 0 & -0.0453 & 0.0002 \\ -0.0143 & 0 & -0.0006 & 0 \\ -0.0040 & 0.0041 & -0.0009 & 0 \\ 0.0024 & 0.0005 & 0.0016 & 0 \\ 0.1376 & 0 & 0.0258 & 0 \\ 1.6160 & 0 & 0.0784 & 0 \\ 2.5739 & 0 & 0.1481 & 0 \\ 0.1317 & 0.3059 & -0.0013 & 0.9126\end{array}$

Jump on First Bid

Percent Time of Bid

Number of Bidders

List Price in Increments

${ }^{\mathrm{a}}$ For 2-5 Units Available both dummy variables $=0$.

Minimum Bid In Increments

6-11 Units Available ${ }^{\mathrm{a}}$

12-61 Units Available

Dealer Presence

Logistic regression pseudo R-squared $=0.089$, OLS regression adjusted Rsquared $=0.147, \mathrm{p}$-values are two-tailed tests, $\mathrm{n}=8015$. 
Table 7 OLS Regression of Total Number of Bids per Auction

\begin{tabular}{|c|c|c|c|c|c|c|}
\hline & \multirow{2}{*}{\multicolumn{2}{|c|}{$\begin{array}{c}\text { Panel } 1 \\
\text { No Interaction Term } \\
\text { Coefficients p-value }\end{array}$}} & \multicolumn{2}{|c|}{$\begin{array}{c}\text { Panel } 2 \\
\text { With Interaction Term }\end{array}$} & \multicolumn{2}{|c|}{$\begin{array}{c}\text { Panel } 3 \\
\text { No Avg. Jump Term }\end{array}$} \\
\hline & & & Coefficients & p-value & Coefficients & p-value \\
\hline Intercept & -9.6555 & 0 & -11.8170 & 0 & -14.1217 & 0 \\
\hline $\begin{array}{l}\text { Avg. Magnitude of Jump } \\
\text { Bids in Increments a }\end{array}$ & -2.7880 & 0 & -1.7164 & 0.1066 & - & - \\
\hline Number of Bidders & 1.0412 & 0 & 1.0335 & 0 & 1.0164 & 0 \\
\hline List Price in Increments & 0.1242 & 0 & 0.1416 & 0 & .1497 & 0 \\
\hline Min. Bid In Increments & 0.9893 & 0 & 0.9872 & 0 & 1.0138 & 0 \\
\hline 6-11 Units Available ${ }^{\mathrm{b}}$ & 3.9782 & 0.1042 & 3.5627 & 0.1480 & 2.8870 & 0.2362 \\
\hline 12-61 Units Available ${ }^{\mathrm{b}}$ & 6.3039 & 0.0396 & 6.8032 & 0.0274 & 7.3359 & 0.0175 \\
\hline Dealer Presence & 0.3382 & 0.8766 & 0.5459 & 0.8022 & .7936 & 0.7165 \\
\hline $\begin{array}{l}\text { Avg. Mag. of Jump Bids } \\
\text { x List Price in Increments }\end{array}$ & 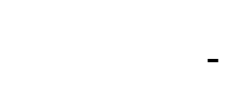 & 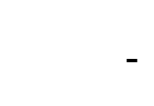 & -0.0057 & 0.2014 & -.0115 & 0 \\
\hline
\end{tabular}

Table A1 OLS Regression of Magnitude of Bid Increase, Conditional on a Jump Bid Being Observed

\begin{tabular}{lrrrr} 
& \multicolumn{2}{c}{ Full Model } & \multicolumn{2}{c}{ Without N Bidders } \\
& Coefficients & p-value & Coefficients & p-value \\
Intercept & 4.1670 & 0 & 4.0205 & 0 \\
Percent Time of Bid & -0.0369 & 0 & -0.0367 & 0 \\
Number of Bidders & 0.0107 & 0 & - & - \\
List Price in Increments & 0.0093 & 0 & 0.0125 & 0 \\
Minimum Bid In Increments & 0.0029 & 0.8290 & -0.0386 & 0.0017 \\
6-11 Units Available & -0.2425 & 0.4393 & 0.0153 & 0.9612 \\
12-61 Units Available & -0.9307 & 0.0086 & 0.2350 & 0.4511 \\
Dealer Presence & 0.0776 & 0.6433 & 0.3269 & 0.0476
\end{tabular}

${ }^{\text {a }}$ For 2-5 Units Available both dummy variables $=0$.

Adjusted R-squared $=0.163$ for full model, 0.149 for reduced model, $\mathrm{p}$-values are two-tailed tests, $\mathrm{n}=2531$. 